\title{
Substituição do milho moído por casca de soja na ração de vacas leiteiras em confinamento ${ }^{1}$
}

\author{
Alexandre Mendonça Pedroso ${ }^{2}$, Flávio Augusto Portela Santos ${ }^{3}$, Carla Maris Machado \\ Bittar $^{3}$, Alexandre Vaz Pires ${ }^{3}$, Junio Cesar Martinez ${ }^{4}$
}

${ }^{1}$ Trabalho financiado pela FAPESP.

2 Doutor em Ciência Animal e Pastagens pela ESALO/USP.

${ }^{3}$ Departamento de Zootecnia da ESALQ/USP.

${ }^{4}$ Doutorando do Departamento de Zootecnia da ESALQ/USP.

RESUMO - Trinta e seis vacas holandesas no terço médio da lactação, 123 dias em lactação (DEL), foram utilizadas para avaliar a substituição do milho moído (MM) por casca de soja (CS) em rações contendo silagem de milho como volumoso principal e polpa cítrica como parte da fonte energética. Foram avaliadas rações com 0, 10 e $20 \%$ de substituição do milho moído por casca de soja na ração, na MS da ração completa (\%MS): CS 0 - 0\% de CS e 20\% de MM; CS 10: 10\% de CS e 10\% de MM; e CS 20 - 20\% de CS e 0\% MM. Características de desempenho e metabolismo como consumo de MS, produção e composição do leite, concentrações de N-uréico no leite e níveis de glicose plasmática foram avaliadas. As vacas foram distribuídas a um delineamento experimental em quadrado latino $3 \times 3$, com de 12 repetições e de acordo com a produção de leite, DEL e a paridade. A inclusão de CS nas rações não afetou o consumo de MS (22,84 kg/dia), a produção de leite (28,33 kg/dia) ou a produção de leite corrigida para 3,5 \% gordura (28,48 kg/dia). No entanto, aumentou linearmente a produção total de gordura (kg/dia) e a decresceu linearmente a concentração de N-uréico no leite. A substituição do milho moído por casca de soja na alimentação de vacas leiteiras pode ser uma alternativa interessante, desde que o preço do subproduto seja competitivo.

Palavras-chave: produção e composição do leite, resíduos fibrosos, ruminantes, subprodutos, vacas em lactação

\section{Replacement of ground corn by soybean hulls in the diets for confined lactating cows}

\begin{abstract}
Thirty six mid lactating Holstein cows, 123 days in milk (DIM), were used to evaluate the substitution of ground corn (GC) by soybean hulls (SH) for in total mixed diets containing corn silage as the main forage source and citrus pulp as part of the energy source. The replacement of 0, 10 and 20\% of ground corn by soybean hulls in total mixed diets (\%DM) were evaluated: SH 0 - 0\% SH and 20\% GC, CS 10: 10\% SH and 10\% GC, and CS $20-20 \%$ SH and 0\% GC. Performance and metabolism characteristics such as dry matter intake, milk yield and composition, milk urea $\mathrm{N}$ concentration, and plasma glucose were evaluated. Cows were assigned 3 × 3 Latin Square experimental design, with 12 replications, according to milk yield, DIM and parity. No effects were observed by the inclusion of SH in the diets on DM intake (22.84 kg/day), milk yield (28.33 kg/day) or 3.5\% fat corrected milk (28.48 kg/day). However, linearly increased total milk fat production and linearly decreased MUN concentration in milk. The replacement of ground corn per soybean hulls in the feeding of lactating cows could be good alternative since byproduct cost be competitive.
\end{abstract}

Key Words: byproducts, fibrous feeds, lactating cows, milk production and composition, ruminants

\section{Introdução}

A crescente demanda pela utilização mais racional e sustentável dos recursos alimentícios em todo o mundo tem aumentado o número de pesquisas sobre a utilização de ingredientes alternativos na nutrição animal como forma de evitar a utilização de alimentos usados em larga escala na alimentação humana. Neste contexto, a substituição de grãos de cereais, em especial o milho, por outras fontes de energia na alimentação de ruminantes torna-se de grande importância.
Entre as possibilidades, a casca de soja constitui alternativa interessante para substituir, em parte, o milho em grão em dietas para vacas em lactação. Esse subproduto é composto principalmente de fibras, que tem pouco valor na alimentação humana e no uso industrial. No entanto, suas características fisico-químicas, a facilidade de aquisição em algumas regiões e seu preço competitivo tornam a CS um ingrediente atrativo para uso em rações para gado leiteiro.

Apesar de o teor energético atribuído à casca de soja ser inferior (NRC, 2001), experimentos têm demonstrado 
que sua substituição pelo milho na dieta não altera o desempenho dos animais. Macgregor et al. (1976) substituíram o milho moído por CS em níveis de até 53,7\% em rações à base de silagem de alfafa e não observaram diferenças no consumo de MS e MS digestível, na produção de leite corrigida para $4 \%$ de gordura, no teor de gordura do leite, na digestibilidade da MS (média 64\%) ou na produção de ácidos graxos voláteis no rúmen. Esses autores concluíram que a CS, em comparação ao milho, forneceu a mesma quantidade de energia líquida para lactação.

Efeito semelhante foi observado por Nakamura \& Owen (1989) em vacas de alta produção alimentadas com ração completa ( $50 \%$ silagem de alfafa e $50 \%$ concentrado) contendo CS em substituição a 0,50 ou $95 \%$ do milho no concentrado. Não foram observadas diferenças no consumo de MS, na produção de leite ou de leite corrigida para 3,5\% de gordura nem na eficiência alimentar. A digestibilidade da MS das rações com milho (70\%) e milho-casca (69\%) foi superior à da ração com casca de soja na forma exclusiva (61\%). As reduções nas digestibilidades da fibra e da MS em rações contendo casca de soja têm sido atribuídas ao aumento na taxa de passagem, em decorrência do reduzido tamanho de partícula da casca de soja (Santos et al., 2002).

Em estudo realizado por Ipharraguerre et al. (2002a), a substituição de 10, 20, 30 e 40\% do milho por CS em rações à base de silagem de milho e silagem de alfafa ( $46 \%$ da MS) não afetou a produção de leite ou o consumo de MS em vacas de alta produção. Entretanto, a inclusão de CS resultou em redução linear $(\mathrm{P}<0,06)$ no consumo de MS à medida que aumentou o nível de inclusão do subproduto. Outros trabalhos com substituição do milho ou outros ingredientes do concentrado por casca de soja em rações para vacas em lactação comprovam não que não há efeito no consumo de MS e na produção e composição do leite (Coomer et al., 1993; Assis et al., 2004)

A composição do leite pode ser alterada com a substituição de milho por casca de soja. Em trabalhos revisados por Nakamura \& Owen (1989) e Pantoja et al. (1994), esses autores observaram aumento no teor de gordura com concomitante redução na produção de leite e manutenção da produção de leite corrigida para gordura.

O teor de proteína do leite diminuiu significativamente com a substituição dos grãos de cereais por CS nos trabalhos realizados por Firkins \& Eastridge (1992), Sarwar et al. (1992) e Pantoja et al. (1994). Segundo Sarwar et al. (1992), esta resposta pode ser parcialmente explicada pelo reduzido teor de carboridratos não-estruturais (CNE) de rações contendo altos níveis de CS, o que pode limitar a síntese de proteína microbiana no rúmen e reduzir o aporte de proteína metabolizável para o intestino delgado (ID), limitando a disponibilidade de aminoácidos na glândula mamária.

Objetivou-se neste trabalho estudar os efeitos da inclusão de três níveis de CS (0, 10 e 20\% da MS total) em substituição parcial ou total ao milho moído em rações contendo silagem de milho de média qualidade e polpa cítrica sobre a produção e composição do leite, o consumo de matéria seca e os parâmetros sanguíneos.

\section{Material e Métodos}

O experimento foi conduzido no Departamento de Zootecnia da Escola Superior de Agricultura Luiz de Queiroz, Universidade de São Paulo (ESALQ/USP), em Piracicaba, SP, nos meses de abril a junho de 2003. Foram utilizadas 36 vacas da raça Holandesa, com média de 535 kg de peso vivo, escore de condição corporal médio de 2,89, período médio de lactação de 123 dias e produção média de leite de $25 \mathrm{~kg} /$ dia, estabuladas em sistema free-stall. Em todos os animais foram aplicadas injeções de somatotropina bovina recombinante (Lactotropin ${ }^{\circledR}$, Elanco Saúde Animal) a cada dez dias.

Neste trabalho foram avaliados níveis crescentes de inclusão de casca de soja (CS) em substituição ao milho moído na MS da ração completa: CS 0: 0\% de CS e 20\%; CS 10: 10\% de CS e 10\% de MM; e CS 20: 20\% de CS e 0\% de MM.

As rações foram formuladas segundo o NRC (2001) para serem isoprotéicas. Os ingredientes utilizados foram silagem de milho, feno de coastcross, milho moído fino, polpa cítrica peletizada, casca de soja, farelo de soja, uréia, suplemento mineral e vitamínico e bicarbonato de sódio (Tabela 1). Uma vez que ao longo de experimento foram utilizadas diferentes partidas de milho, polpa cítrica e farelo de soja, as rações experimentais apresentaram variações, inclusive no teor de $\mathrm{PB}$, em relação às formuladas inicialmente. O teor de FDN das rações foi superior ao planejado e, conseqüentemente, o teor de CNF foi inferior, em razão das diferenças na composição da silagem utilizada ao longo do ensaio.

Durante o período pré-experimental (14 dias), todas as vacas receberam a mesma ração. Os animais foram agrupados nos tratamentos conforme a produção de leite, o estádio de lactação e a ordem de parição. O período experimental teve duração de 42 dias, divididos em três subperíodos de 14 dias. Os 11 primeiros dias de cada subperíodo foram destinados à adaptação dos animais às rações e os outros três para coleta de dados.

Os animais foram pesados e o escore de condição corporal foi avaliado no início e ao final de cada período 
Tabela 1 - Composição das rações experimentais (\% MS) Table 1 - Composition of the experimental diets (\% DM)

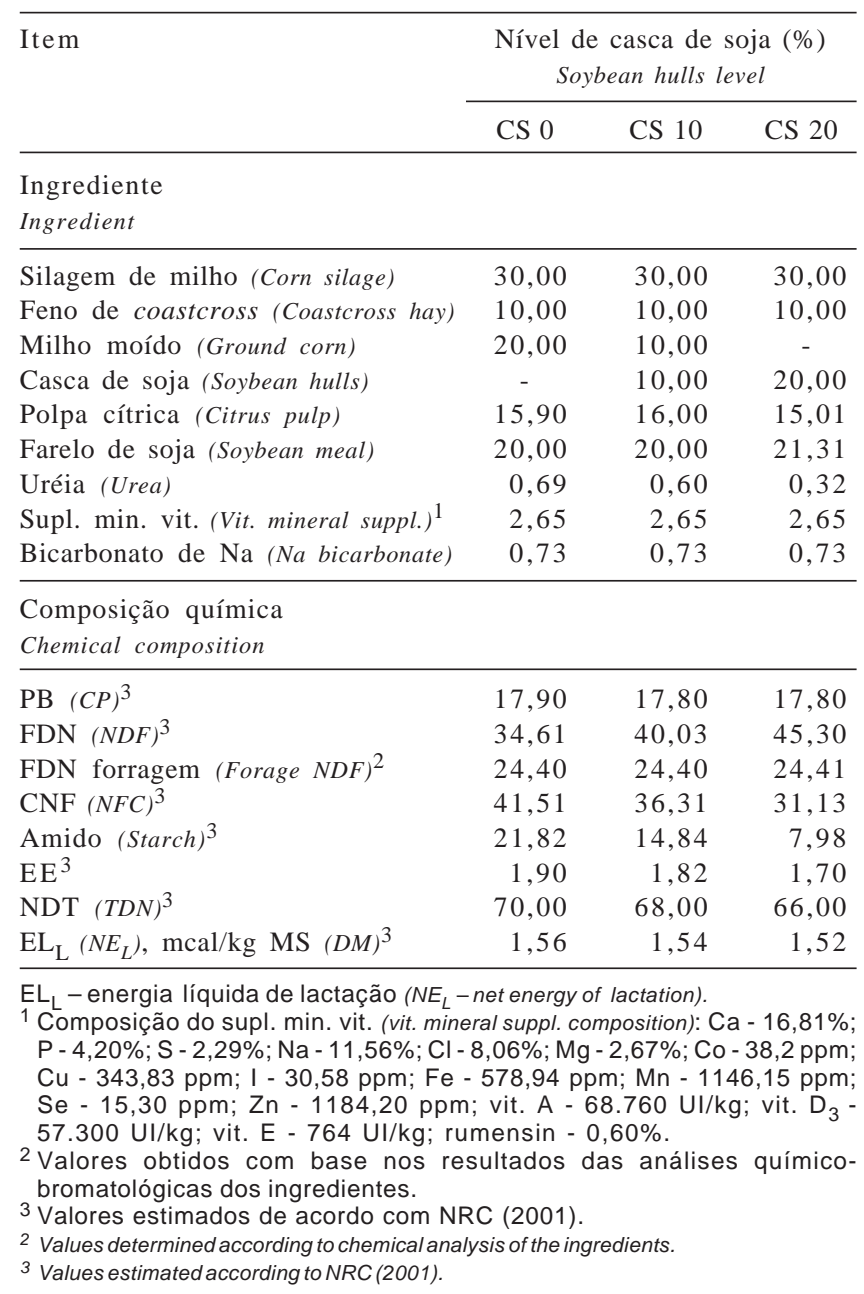

experimental utilizando-se a escala de 1 a 5 , de acordo com Wildman et al. (1982). Entretanto, uma vez que o fornecimento de cada ração durou 14 dias (subperíodo), esses parâmetros não foram analisados, em virtude da baixa probabilidade de efeito da ração. Portanto, os dados foram utilizados apenas para controle do rebanho experimental.

A ordenha foi realizada duas vezes ao dia (6 e $18 \mathrm{~h})$. As produções de leite individuais foram registradas nos últimos três dias de cada subperíodo utilizando-se medidores do tipo “Mark V" para estimativa da produção total por meio de uma amostragem de $10 \%$ do fluxo de leite durante a ordenha. Amostras de leite de cada vaca foram coletadas também nestes dias, somente na ordenha da tarde, e analisadas quanto aos teores de gordura, proteína, lactose, sólidos totais pelo analisador Bentley 2000 (Bentley Instruments ${ }^{\circledR}$ ) e nitrogênio uréico pelo analisador ChemSpec 150 (Bentley Instruments ${ }^{\circledR}$ ) no Laboratório da Clínica do Leite do Departamento de Zootecnia da ESALQ/USP.

O fornecimento das rações experimentais foi feito duas vezes ao dia ( 6 e $18 \mathrm{~h}$ ) e as sobras de alimento foram pesadas e descartadas diariamente antes do fornecimento do período da tarde. O consumo de alimento foi medido diariamente em grupo, por tratamento, durante os últimos três dias de coleta de dados de cada subperíodo.

A silagem foi amostrada semanalmente e os demais alimentos, no início de cada período de coleta de dados. As amostras de silagem foram armazenadas a $-18^{\circ} \mathrm{C}$ e as subamostras foram secas imediatamente após a amostragem, a $105^{\circ} \mathrm{C}$ por 24 horas, para determinação da MS, a fim de se proceder ao ajuste da formulação das rações. Após o período experimental, as amostras foram secas a $55^{\circ} \mathrm{C}$ (em estufa com circulação forçada por 72 horas) e analisadas quanto aos teores de MS, cinzas (Campos et al., 2004), FDN (Van Soest et al., 1991), PB (AOAC, 1990) e amido, segundo método descrito por Poore et al. (1993).

No último dia de cada subperíodo, 4 horas após alimentação, amostras de sangue foram coletadas da veia coccígea utilizando-se tubos vacuolizados contendo fluoreto de sódio como antiglicolítico e oxalato de potássio como anticoagulante. As amostras foram centrifugadas em $2.000 \mathrm{~g}$ por 20 minutos e armazenadas a $-18^{\circ} \mathrm{C}$ para posterior determinação das concentrações de glicose pelo Analisador Bioquímico YSI 2700S (Yellow Springs Instrument Co. Inc., Ohio, USA).

O delineamento estatístico utilizado foi o de quadrados latinos $3 \times 3$ repetidos (Snedecor \& Cochran, 1989), com 36 animais distribuídos em 12 quadrados latinos, agrupados de acordo com o número de lactações (multíparas ou primíparas), a produção de leite e os dias em lactação medidos durante o período pré-experimental.

Os dados de consumo foram analisados como um quadrado latino simples, no qual cada lote de animais, de cada tratamento, foi considerado uma unidade experimental, uma vez que o consumo de alimento foi medido em grupo e não individualmente (Santos et al., 2006). Para análise dos dados de produção e composição do leite, além dos parâmetros sangüíneos, foram utilizados dados individuais.

Os dados foram analisados pelo PROC GLM (General Linear Models) do programa estatístico SAS (2000), versão 8.2 para Windows. A análise de polinômios ortogonais foi feita testando-se os efeitos linear e quadrático dos níveis de CS (Snedecor \& Cochran, 1989), considerando o nível de significância de 5\% para a probabilidade do teste $\mathrm{F}$ na análise de variância e de até $10 \%$ como tendência.

Todos os dados foram testados para se verificar a distribuição normal dos erros, utilizando-se o PROC UNIVARIATE (SAS, 2000). Os dados que apresentaram erros fora do intervalo de \pm 3 desvios foram descartados da análise estatística (Snedecor \& Cochran, 1989). 


\section{Resultados e Discussão}

O consumo médio de MS foi de 22,84 kg/dia (Tabela 2), valor elevado para o nível de produção observado (28,33 kg/vaca/dia), mas compatível com o estádio médio de lactação das vacas, conforme o NRC (2001). De acordo com o peso médio dos animais durante o experimento, este consumo representa aproximadamente $4,2 \%$ do PV e pode ser considerado alto. Apesar da considerável variação numérica, não foram observadas diferenças significativas entre os tratamentos para o consumo de MS, o que está de acordo com a maioria dos trabalhos revisados (Assis et al., 2004; Bernard \& McNeill, 1991; Macgregor \& Owen, 1976; Nakamura \& Owen, 1989). Em revisão realizada por Ipharraguerre \& Clark (2003), em 13 dos 15 trabalhos analisados, o consumo de MS também não diferiu quando a CS substituiu os grãos nas rações.

Ipharraguerre et al. (2002) testaram quatro níveis de substituição do milho por casca de soja (10, 20, 30 e 40\%) e não observaram diferenças entre o consumo de MS da ração controle em comparação àquelas contendo CS em vacas em lactação. Entretanto, houve redução linear no consumo de MS entre as rações com CS à medida que aumentaram os níveis de inclusão do subproduto. No entanto, as maiores reduções ( $1 \mathrm{~kg} / \mathrm{dia}$ ) foram observadas quando a CS representava mais de 30\% da MS total, valor superior ao utilizado neste ensaio. O efeito da CS na redução do consumo de MS parece ocorrer somente quando este ingrediente é incluído em taxas mais elevadas que a utilizada neste estudo.
Miron et al. (2004b) testaram a inclusão de uma mistura 2:1 de CS e farelo de glúten de milho (FGM-21) em substituição a grãos de cevada e milho e observaram aumento no consumo de MS de 2,3 kg MS/vaca/dia para a ração com os subprodutos. Os autores consideraram como uma das possibilidades para explicar essa ocorrência o fato de as rações sem o subproduto conterem teor elevado de amido de alta degradabilidade (16,7\% de grãos de cevada moídos na MS), o que pode reduzir a taxa e a extensão de degradação da FDN, prejudicando o consumo. Outra possibilidade é o maior aporte de energia proporcionado pela ração com grãos ter exercido efeito maior de saciedade, inibindo a ingestão.

Neste trabalho, a ração controle apresentava menores concentrações de amido em virtude da inclusão de polpa cítrica. Dados obtidos por Santos et al. (2001) e Nussio et al. (2002) demonstraram efeitos benéficos da substituição de parte do milho por polpa cítrica em rações para vacas leiteiras. Assim, o alto consumo observado também na ração controle deve ser conseqüência do menor teor de amido desta ração (21\%) em comparação a rações tradicionalmente utilizadas e contendo até $28 \%$ de amido (Santos et al., 2001; Nussio et al., 2002).

Não houve efeito das dietas sobre a produção de leite, o que está de acordo com quase todos os estudos disponíveis na literatura. Segundo revisão de Ipharraguerre \& Clark (2003) com dados de dez ensaios de produção, a correlação entre a inclusão da CS nas rações em substituição a grãos de cereais e a produção de leite é baixa e não significativa $(\mathrm{P}=0,51)$. Também em trabalhos realizados por Assis et al. (2004), Miron et al. (2004a) e Miron et al. (2004b), a substi-

Tabela 2 - Consumo de MS, produção e composição do leite, concentrações de nitrogênio uréico no leite e de glicose no plasma Table 2 - DM intake, milk production and composition, milk urea nitrogen and plasma glucose concentration

\begin{tabular}{|c|c|c|c|c|c|c|}
\hline \multirow[t]{2}{*}{ Item $^{1}$} & \multicolumn{3}{|c|}{$\begin{array}{l}\text { Nível de casca de soja }{ }^{2} \\
\text { Soybean hulls level }\end{array}$} & \multirow[t]{2}{*}{$\begin{array}{c}\mathrm{EPM}^{2} \\
S M E\end{array}$} & \multicolumn{2}{|c|}{$\mathrm{P}^{3}$} \\
\hline & CS 0 & CS 10 & CS 20 & & $\mathrm{~L}$ & Q \\
\hline CMS (kg MS/anim.d) (DMI, kg DM/anim.day) & 23,53 & 21,76 & 23,22 & 2,056 & ns & ns \\
\hline Leite (kg/d) (Milk) & 28,21 & 28,28 & 28,51 & 0,260 & ns & ns \\
\hline LCG 3,5 (kg/d) (FCM 3.5) & 28,20 & 28,40 & 28,85 & 0,271 & 0,097 & ns \\
\hline Gordura (\%) (Fat) & 3,53 & 3,51 & 3,57 & 0,033 & ns & ns \\
\hline Gordura (kg/d) (Fat) & 0,98 & 0,99 & 1,02 & 0,012 & 0,047 & ns \\
\hline Proteína (\%) (Protein) & 3,09 & 3,09 & 3,07 & 0,010 & ns & ns \\
\hline Proteína (kg/d) (Protein) & 0,86 & 0,86 & 0,86 & 0,009 & ns & ns \\
\hline Relação gordura/proteína (Fat/protein ratio) & 1,14 & 1,14 & 1,17 & 0,013 & 0,10 & ns \\
\hline Lactose (\%) (Lactose) & 4,32 & 4,33 & 4,33 & 0,009 & ns & ns \\
\hline Lactose (kg/d) (Lactose) & 1,22 & 1,23 & 1,23 & 0,012 & ns & ns \\
\hline Sólidos totais (\%) (Total solids) & 11,79 & 11,83 & 11,87 & 0,041 & ns & ns \\
\hline Sólidos totais (kg/d) (Total solids) & 3,32 & 3,33 & 3,37 & 0,032 & ns & ns \\
\hline NUL (mg/dL) (MUN) & 16,67 & 15,95 & 15,83 & 0,131 & $<0,001$ & 0,067 \\
\hline Glicose plasmática (mg/dL) (Plama glicose) & 52,08 & 52,17 & 51,62 & 1,274 & ns & ns \\
\hline
\end{tabular}

${ }^{1}$ CMS - Consumo de MS, LCG 3,5 - produção de leite corrigida para 3,5\% de gordura; NUL - nitrogênio uréico no leite.

2 EPM - erro-padrão da média (SME - standard mean error).

3 Probabilidade dos contrastes para (L) efeito linear e (Q) efeito quadrático (desvio da linearidade) para os teores de CS testados; NS - não-significativo.

${ }^{1}$ DMI-DM intake, FCM 3.5 - 3.5 \%fat corrected milk; MUN - milk urea nitrogen.

3 Probability of contrasts for (L) linear effect and (Q) quadratic effect (linearity deviation) for CS doses tested; ns - not significant. 
tuição de grãos de cereais por CS não ocasionou alterações na produção de leite.

No entanto, observou-se tendência $(\mathrm{P}<0,10)$ de aumento na produção de LCG 3,5\% neste ensaio, diferente do que se observa na maioria dos trabalhos revisados, mas semelhante ao observado em dois trabalhos. Miron et al. (2004b) observaram aumento de $4 \mathrm{~kg} /$ dia na produção de leite corrigida para 4\% de gordura (LCG 4\%), possivelmente em razão do baixo teor de FDN e do alto teor de amido da ração controle, que continha grãos de milho e cevada causando redução significativa no teor de gordura do leite.

Em pesquisa realizada por Sarwar et al. (1992), também houve aumento linear na produção de LCG 4\% quando os níveis de CS em substituição ao milho passaram de 18,6 para $34 \%$ da MS total. Esse efeito, no entanto, foi confundido com a adição de gordura (soja tostada) às rações com CS, realizada com o objetivo de manter a concentração energética das dietas, portanto, houve tendência de aumento linear na produção de leite, o que afetou a produção de LCG 4\%.

Ipharraguerre \& Clark (2003) demonstraram haver correlação não-significativa entre a adição de CS às rações em substituição ao milho e a produção de LCG 4\%, resultado da falta de efeito da CS sobre a produção de leite e o teor de gordura do leite.

Neste estudo, não houve efeito das dietas sobre o teor de gordura do leite $(\mathrm{P}>0,10)$. Entretanto, o pequeno aumento numérico pode ser responsável pelo aumento linear na produção total de gordura do leite $(\mathrm{P}<0,05)$. Ipharraguerre \& Clark (2003) apontam falta de consistência nos efeitos da CS sobre a gordura do leite, o que está relacionado às pequenas variações das rações experimentais em relação aos controles ( $+0,11$ unidades percentuais). Em apenas quatro dos ensaios avaliados houve diferença significativa, no entanto, em três desses estudos nos quais as rações controle continham quantidade elevada de grãos de milho (acima de 35\% da MS total), a inclusão de CS restabeleceu os teores de gordura, o que não pode ser considerado aumento real no teor de gordura. Os resultados obtidos neste ensaio estão de acordo com o relatado por esses autores de que a FDN da CS é efetiva em manter ou até aumentar o teor de gordura do leite.

Contrariando a maior parte dos dados relatados na literatura, neste trabalho não houve efeito da substituição do milho pela CS sobre o teor ou a síntese de proteína do leite $(\mathrm{P}>0,10)$. A maioria dos trabalhos revisados (Assis et al., 2004; Firkins \& Eastridge, 1992; Ipharraguerre et al., 2002a; Miron et al., 2004a; Miron et al., 2004b; Pantoja et al., 1994; Sarwar et al., 1992) indica teor de proteína do leite mais baixo para as dietas contendo CS em substituição a grãos de cereais. Ipharraguerre \& Clark (2003) demonstraram em revisão que a redução no teor de proteína do leite entre os trabalhos compilados variou de 0,8 a $8 \%$ quando a CS substituiu o milho em grão em níveis de 18 a $48 \%$ da MS total, respectivamente. Essa resposta poderia ser explicada, ao menos em parte, pelo menor teor de CNE, especialmente amido, das rações contendo altos níveis de CS, que podem limitar a síntese de proteína microbiana no rúmen por reduzirem o aporte de proteína metabolizável para o intestino delgado, o que limitaria a disponibilidade de aminoácidos na glândula mamária.

Neste trabalho, mesmo com redução considerável no teor de amido das rações contendo CS, não houve alteração na proteína do leite, possivelmente porque o teor de amido da ração controle (22\%) não foi elevado o suficiente para viabilizar uma resposta. Mansfield \& Stern (1994) reportaram que, mesmo com a redução no teor de CNE de 33 para 23\% com a substituição total do milho pela CS (30\% da MS), não houve diferenças na eficiência de síntese de proteína microbiana. O mesmo padrão foi observado por Ipharraguerre et al. (2002b), em trabalho no qual a substituição do milho por CS (até $40 \%$ da MS total) causou redução no teor de CNE de 36 para $16 \%$.

Outra possibilidade para explicar esse menor teor de proteína no leite seria a redução no teor de metionina (Met) na proteína metabolizável que chega no intestino delgado, mantendo o nível abaixo do recomendado por Schwab \& Ordway (2004), uma vez que a CS contém menos metionina que o milho. Essa hipótese foi sugerida por Ipharraguerre \& Clark (2003), mas é válida apenas para vacas do início até o meio da lactação e quando o nível de CS é superior a 25\% da MS total. Neste experimento as vacas apresentavam, em média, 123 DEL ao início do ensaio e o nível máximo de CS foi $20 \%$ da MS total, portanto, é pouco provável que esta hipótese se aplique a esse caso.

Os valores referentes à gordura e proteína do leite resultaram em tendência de aumento linear na relação gordura/proteína à medida que se adicionava CS às rações. Embora os trabalhos revisados não apresentem comparações para esse parâmetro, espera-se que, com a tendência de redução nos valores de proteína e com a falta de consistência nos dados referentes à gordura, os valores para a relação gordura/proteína sejam mais elevados nas rações em que a CS substitui o milho em grãos.

O teor de lactose no leite não variou entre os tratamentos, o que está de acordo com dados descritos por Assis et al. (2004) e por Miron et al. (2004b). Miron et al. (2004a) não observaram diferenças neste parâmetro com a substituição das fontes de amido pela CS. As comparações referentes ao teor de lactose do leite ficam bastante prejudicadas, pois a maior parte dos trabalhos revisados não apresenta essa variável. 
Em razão da pouca variação nos componentes do leite, os valores relativos à concentração total de sólidos no leite também não diferiu entre as dietas. Os dados de literatura são escassos com relação a discussão deste parâmetro. Entretanto, em estudo realizado por Ipharraguerre et al. (2002a), a adição de CS em substituição à fonte de amido causou aumento linear no teor de sólidos totais do leite.

A concentração de N-uréico no leite foi linearmente reduzida à medida que se incluiu a CS nas rações experimentais em substituição ao milho. Os valores de NUL observados neste ensaio foram relativamente elevados (média de 16,15 mg/dL), o que pode estar associado ao elevado teor de PB das rações e ao baixo teor de amido, havendo sobra de proteína no rúmen. A associação desses dois fatores (baixo teor de amido e sobra de proteína degradável no rúmen) resulta em menor eficiência de utilização da proteína e, conseqüentemente, em menor produção de proteína microbiana. O teor de nitrogênio uréico no leite se correlaciona ao teor plasmático, que, por sua vez, pode ser afetado pelo teor de nitrogênio amoniacal no fluido ruminal e pela proteína metabolizável com perfil inadequado de aminoácidos essenciais (NRC, 2001). Contudo, como as rações com CS apresentam menor teor de amido, esperavam-se valores mais elevados de NUL, o que não foi observado.

foram previstos valores mais elevados de NUL, o que não foi observado.

A concentração plasmática de glicose foi, em média, de 51,96 mg/dL e não diferiu entre as dietas. Este parâmetro é normalmente de difícil resposta às dietas, uma vez que sofre controle homeostático. Entretanto, a maior disponibilidade de carboidratos de alta degradabilidade, como é o caso da ração controle, pode resultar em aumentos na disponibilidade de glicose, oriunda de gliconeogênese a partir de produtos finais de fermentação, principalmente propionato, e conseqüentemente aumentar a produção de leite (Theurer et al., 1999). Neste caso, em nenhum dos trabalhos revisados avaliou-se esse parâmetro, mas os valores estão dentro da faixa de variação considerada normal, entre 42 e 74 mg/dL (Fraser, 1991).

\section{Conclusões}

A substituição do milho em grão por casca de soja nos teores testados e nas condições experimentais estabelecidas neste estudo não causou alterações na produção de leite, no consumo de MS e na concentração plasmática de glicose, mas resultou em discretas alterações na composição do leite. Desse modo, o uso deste subproduto como substituto do milho em rações para vacas leiteiras produzindo em torno de $28 \mathrm{~kg}$ de leite ao dia pode ser interessante, desde que seu preço seja competitivo ao do cereal.

\section{Literatura Citada}

ASSIS, A.J.; CAMPOS, J.M.S.; OLIVEIRA, A.S. et al. Casca de soja em dietas de vacas leiteiras. I - Consumo, variação de peso, produção e composição do leite. In: REUNIÃO ANUAL DA SOCIEDADE BRASILEIRA DE ZOOTECNIA, 41., 2004, Campo Grande. Anais... Campo Grande: Sociedade Brasileira de Zootecnia, 2004. (CD-ROM).

ASSOCIATION OF OFFICIAL ANALYTICAL CHEMISTS - AOAC. Official methods of analysis. 15.ed. Arlington: 1990. v.1, 1117p.

BERNARD, J.K.; MCNEILL, W.W. Effect of high fiber energy supplements on nutrient digestibility and milk production of lactating dairy cows. Journal of Dairy Science, v.74, n.3, p.991-995. 1991.

CAMPOS, F.P.; NUSSIO, C.B.; NUSSIO, L.G. Métodos de análise de alimentos. Piracicaba: Fundação de Estudos Agrários Luiz de Queiroz, 2004. 135p.

COOMER, J.C.; AMOS, H.E.; WILLIAMS, C.C. et al. Response of early lactation cows to fat supplementation in diets with different nonstructural carbohydrate concentrations. Journal of Dairy Science, v.76, n.12, p.3747-3754, 1993.

FIRKINS, J.L.; EASTRIDGE, M.L. Replacement of forage or concentrate with combinations of soyhulls, sodium bicarbonate, or fat for lactating dairy cows. Journal of Dairy Science, v.75, p.2752-2760, 1992.

FRASER, C. M. Manual merck de veterinária. 6.ed. São Paulo: Roca, 1991. 2169p.

IPHARRAGUERRE, I.R.; CLARK, J.H. Soyhulls as an alternative feed for lactating dairy cows: a review. Journal of Dairy Science, v.86, n.4, p.1052-1073, 2003.

IPHARRAGUERRE, I.R.; IPHARRAGUERRE, R.R.; CLARK, J.H. Performance of lactating dairy cows fed varying amounts of soyhulls as a replacement for corn grain. Journal of Dairy Science, v.85, n.11, p.2905-2912, 2002a.

IPHARRAGUERRE, I.R.; SHABI, Z.; CLARK, J.H. et al. Ruminal fermentation and nutrient digestion by dairy cows fed varying amounts of soyhulls as a replacement for corn grain. Journal of Dairy Science, v.85, n.11, p.2890-2904, 2002b.

MACGREGOR, C.A.; OWEN, F.G. Effect of increasing ration fiber with soybean mill run on digestibility and lactation performance. Journal of Dairy Science, v.59, p.682-689, 1976.

MANSFIELD, H.R.; STERN, M.D. Effects of soybean hulls and lignosulfonate-treated soybean meal on ruminal fermentation in lactating dairy cows. Journal of Dairy Science, v.77, p.1070-1083, 1994.

MIRON, J.; YOSEF, E.; NIKBACHAT, M. et al. Feeding behavior and performance of dairy cows fed pelleted nonroughage fiber byproducts. Journal of Dairy Science, v.87, n.5, p.13721379, 2004a.

MIRON, J.; NIKBACHAT, M.; ZENOU, A. et al. Lactation performance and feeding behavior of dairy cows supplemented via automatic feeders with soy hulls or barley based pellets. Journal of Dairy Science, v.87, n.11, p.38083815, 2004b.

NAKAMURA, T.; OWEN, F.G. High amounts of soyhulls for pelleted concentrate diets. Journal of Dairy Science, v.72, p.988-994,1989.

NATIONAL RESEARCH COUNCIL - NRC. Nutrient requirements of dairy cattle. 7.rev.ed. Washington, D.C.: National Academy Press, 2001. 381p.

NUSSIO, C.M.B.; SANTOS, F.A.P.; PIRES. A.V. et al. Fontes de amido de diferentes degradabilidades e sua substituição por polpa de citrus em dietas para vacas leiteiras. Acta Scientarium, v.24, n.4, p.1079-1086, 2002. 
PANTOJA, J.; FIRKINS, J.L.; EASTRIDGE, M.L. et al. Effects of fat saturation and source of fiber on site of nutrient digestion and milk production by lactating dairy cows. Journal of Dairy Science, v.77, n.8, p.2341-2356, 1994.

POORE, M.H.; MOORE, J.A.; SWINGLE, R.S. et al. Effect of fiber source and ruminal starch degradability on site and extent of digestion in dairy cows. Journal of Dairy Science, v.76, p.2244, 1993.

SANTOS, G.T.; ZAMBOM, M.A.; ALCALDE, C.R. et al. Degradabilidade in situ da matéria seca, matéria orgânica e energia bruta da casca do grão de soja moída ou peletizada. In: REUNIÃO ANUAL DA SOCIEDADE BRASILEIRA DE ZOOTECNIA, 39., 2002, Recife. Anais... Recife: Sociedade Brasileira de Zootecnia, 2002. (CD-ROM).

SANTOS, F.A.P.; MENEZES JR., M.P.; SIMAS, J.M.C. et al. Processamento do grão de milho e sua substituição parcial por polpa de citros peletizada sobre o desempenho, digestibilidade de nutrientes e parâmetros sangüíneos. Acta Scientarium, v.23, n.4, p.923-931, 2001.

SANTOS, F.A.P.; CARMO, C.A.; MARTINEZ, J.C. et al. Desempenho de vacas em lactação recebendo dietas com diferentes teores de amido total, acrescidas ou não de levedura (Saccharomyces cerevisiae). Revista Brasileira de Zootecnia, v.35, n.4, p.1568-1575, 2006.

SARWAR, M.; FIRKINS, J.L.; EASTRIDGE, M.L. Effects of varying forage or concentrate carbohydrates on nutrient digestibilities and milk production by dairy cows. Journal of Dairy Science, v.75, p.1533-1542, 1992.
STATISTICAL ANALYSIS SYSTEM - SAS. User's guide: statistics. Cary: 2000. 965p.

SCHWAB, C.G.; ORDWAY, R.S. Balancing diets for amino acids: implication on production efficiency and feed costs. In: PENNSYLVANIA STATE DAIRY CATTLE NUTRITION WORKSHOP, 2004, Grantville. Proceedings... Grantville: Pennsylvania State University, 2004. p.1-16.

SNEDECOR, G.W.; COCHRAN, W.G. Statistical methods. 8.ed. Iowa: Iowa State University Press, 1989. 503p.

THEURER, C.B.; HUBER, J.T.; DELGADO, E. et al. Invited review: summary of steam-flaking corn or sorghum grain for lactating dairy cows. Journal of Dairy Science, v.82, p.1950-1959, 1999.

Van SOEST, P.J.; ROBERTSON, J.B.; LEWIS, B.A. Methods for dietary fiber, neutral detergent fiber, and nonstarch polysaccharides in relation to animal nutrition. Journal of Dairy Science, v.74, p.3583, 1991.

WILDMAN, E.E.; JONES, G.M.; WAGNER, P.E. et al. A dairy condition scoring system and its relationship to selected production characteristics. Journal of Dairy Science, v.65, p.495, 1982. 